\title{
SUSTAINABLE VERTICAL URBANISM AS A DESIGN APPROACH TO CHANGE THE FUTURE OF HYPER DENSITY CITIES REDESIGNING THE SKYSCRAPER FROM THE URBAN DESIGN PERSPECTIVE
}

\author{
Ahmed Ehab Abdelsalam AEH ${ }^{1 *}$, Prof. David Nicolson Cole ${ }^{2}$, Prof. Khaled Dewidar ${ }^{3}$ \\ *1,2,3 Sustainable Tall Buildings studio, Department of Architecture and Built Environment, University of Nottingham,
} $U K$

\section{*Corresponding Author: -}

\begin{abstract}
: -
This paper focuses on introducing Sustainable Vertical Urbanism (SVU) as an approach for designing hybrid buildings and upgrading the public realm, making full use of the vertical dimension in hyper density cities. Mixed use tall buildings offer greater potential for contributing to the city economy, vitality and public interaction, compared to closed single-use glassy towers. Mixed use buildings bring new challenges in planning, morphology and technology. Unusual functions can be included in tall buildings such as vertical education, vertical public realm, vertical health care and vertical farming, plus integration with public transport. SVU is a new approach for densification of the city, coping with the pressures of urbanization, transport connectivity, environmental urban health; SVU can change people attitudes to living, working and enjoying culture in the city.
\end{abstract}

Keywords: - Vertical Urbanism, Vertical public realm, City Vitality, Sustainable Tall buildings, Mixed use

\section{(c) $(\$)$}




\section{INTRODUCTION}

The City is never completed: it has beginning but it has no end: it is a work in progress always waiting for new character and functions to be added. Human settlement has developed for centuries in mixed use patterns, combining such different functions as residential, commercial, cultural, educational and industrial into the urban mesh. With urbanization (the flow of rural migrants to the city), every first generation suffers hardship, but they do it for the sake of their future children because they believe in the educational and employment opportunities and the safety of living and working in the city. Before the motorcar, urban architecture developed from Roman origins with the idea of the insulae: a mixed use apartment building, with shops, workshops or stabling below, and living space above, formed into urban blocks with shared light wells and staircases. This pattern of vertical mixed urbanism can be found in Renaissance Italy, Georgian London, Haussmann's Paris, brownstone Manhattan, the tenements of Edinburgh, the shop houses of Singapore, the chawls of Bombay, the Barcelona grid block, the elevated 9-storey shop houses of Hong Kong and many more, on different continents. Since the start of the $20^{\text {th }} \mathrm{C}$, urban functions of living and working have been organized into zones, driven by the demands of urban transportation, as $19^{\text {th }} \mathrm{C}$ cities expanded exponentially in size, with sprawl enabled by the motorcar. With the invention of the metal frame, the elevator, the telephone, the sprinkler and AC electricity, it became possible to rise above the historic urban height of 5-7 stories, and Home Insurance, Chicago, the first modern tall building appeared in 1884 . These were confined to what came to be called the 'central business district'. In the enlightened $21^{\text {st }} \mathrm{C}$, we have acknowledged that mixed-use urban development is an essential and important part of the regeneration and urban renewal process, along with reform of transportation modes. If the many uses of the urban realm are to share land space, then there is a new consciousness of the opportunities in vertical urbanism, stacking functions above each other on the same land plot, instead of sprawling outwards. When we, as citizens or tourists, think of cities, especially the open spaces and mixed use developments that makes cities vibrant, dynamic places, we tend to think in the intuitive level: mostly the ground plane - the tall buildings soar above us, inaccessible to all but the inhabitants. However, when we, as urban designers, use our critical analysis skills to view our cities as multidimensional places, we can see where people spend time on different levels starting from sub-basements of transit systems to the topmost floors of tall buildings, and we can make expert judgements about their best 'fit' to the city, economically, socially and environmentally. People love cities that enable them to spend time meandering on foot, safe from cars, commercial traffic and highways. Citizens and city visitors want easy access to shops and service that fulfil their daily needs, and to cultural facilities that enrich their lives. To create cities that are liveable, dynamic and vibrant, new ways should be considered to create public, open spaces and mixed-use developments within these urban places, above and below, as the Ground plane becomes more valuable and overcrowded. Applying this thinking to our urban fabric in a more encompassing three-dimensional way, we need to re-imagine urbanism and the intersection of people and experience that makes city vibrant in a way that includes the vertical dimension. We can consider our contemporary life style and the increasing combined pressure of urbanization and population growth on our cities - these demand that we redefine our perception of working and living in high rise structures in the city. For us, as urban designers and architects, a whole new 21st century oriented cognitive schema governs our future careers. We must combine consciousness of designing for urbanized megacities with management of climate change and energy.
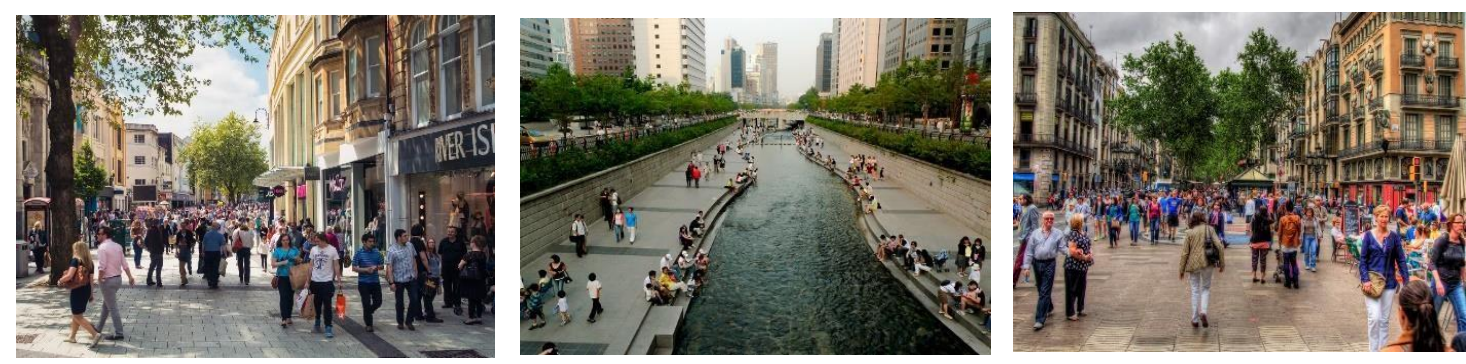

Figure 1. walkable cities with dense street networks, Cardiff, Seoul and Barcelona.

The modern era of tall buildings started in 1885 with the office buildings of Chicago and New York. Normal street-based urban architecture had remained essentially unchanged since the Roman insulae with an average height of 5-7 stories, as in Haussman's Paris or the tenements of Bologna, Berlin and Barcelona. This street form still works successfully for high density cities, although it suffers from traffic congestion. Skyscraper design has gone through a series of evolutionary

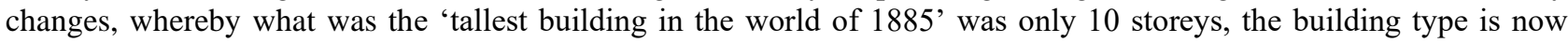
reaching $1000 \mathrm{~m}$ in the Kingdom Tower of Jeddah. Heights have increased, technology and engineering have become far better and much more sophisticated; but most if not all the skyscrapers constructed in the 20th century remain fundamentally the same in-built configuration, as a single use container of stacked floorplates. Their basic planning remains the same - many international style tall buildings are nothing more than a series of stacked trays around a central service core, piled homogeneously and vertically one on top of the others, while at the same time seeking to optimize netto-gross area spatial efficiencies, and satisfying the real estate financial developments investments. (Yeang, 2006). In the $21^{\text {st }}$ century, there is awareness of better ways to design, and yet still achieve economic purposes. As an urban design proposition, it can be an imaginative leap to regard skyscrapers as a 'vertical extension of the city', and to carry out its design in considerably more complex and intense terms. That idea deserves more critical exploration. Skyscraper design needs external, internal and transitional spaces to be similar to those of successful urban spaces found in our cities. 
Tall buildings last a very long time. Only 3 buildings above $160 \mathrm{~m}$ have ever been demolished. If they are designed badly as monocultural containers with inefficient environmental systems, that can be a blemish on the city for many decades until radical refurbishment converts them to mixed use. There have been examples of changes of use in Chicago, New York and London. At the outset of a new tall building, it is a long term cost saving to take into consideration the needs of its future users, because a tall building is more expensive and difficult to adapt over time than replacement of units in a city street. As cities' business and residential precincts become considerably denser, the impact of skyscrapers' design need to be considered. In intensive urban localities, it is an urban design proposition, and not just a closed architectural object for the developer. The space enclosed by the backdrop of surrounding buildings is what the citizen experiences. Tall buildings with permeability at ground plan and a safe level of vertical access to the public could be regarded as a vertical extension of the city. To carry this design idea out is considerably more complex and challenging than the closed building. This is a new territory for the city planner, the urban designer and for the architect - who must persuade the building owner/client of the benefits.
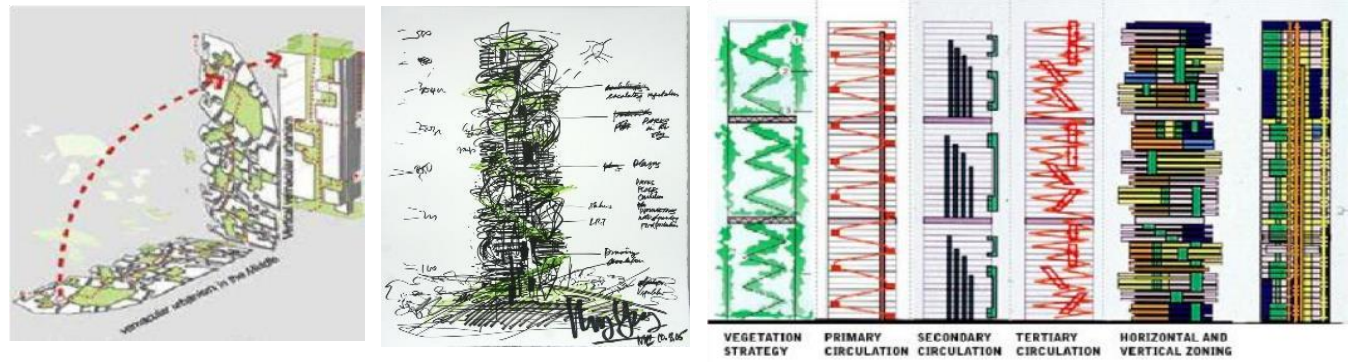

Figure 2. Ken Yeang Sketches, Source: Reinventing the Skyscraper: a vertical theory of urban design.

What is vitally needed is a redefinition for more satisfyingly habitable working and living urban environment: more diverse, greater multiplicity, an environment that recreates those fulfilling aspects, similar to those successful urban spaces found in the ground level. The vertical urban realm also needs networks of plazas, parks, pathways and enclosed spaces in the sky. Contemporary concerns of security and privacy exist, such as the safety of children in vertical schools, the privacy of residents, the commercial security of office tenants. These have to be resolved with card-access systems, smart elevator design, and clarity of the functions, circulation routes and public spaces to ensure that problems do not occur.

When people have the ability of living, working, shopping and recreation in vertical urbanism complexes, they have the opportunity to develop community atmosphere. (Spaces, 2009) For the community atmosphere to be successful it's important to understand the synergy between different functions and the synergy between different way of functional organization in mixed use tall buildings. The form should reflect the functions, starting from planning, organization and facades, instead of enclosing all behind a glass wall. The tall building should no longer be treated as a one block building: it must be treated as a vertical urbanistic organism with identifiable functional elements. The circulation can be designed to transform horizontal mixed-use street blocks in to a sustainable vertical route where each function has its own character and degree of access. This may sound like science fiction, but this is the world changing potential of what started off as a wildly imaginative proposal by Ken Yeang in 2002 (Reinventing the Skyscraper). A combination of growing economy and enlightened city government empowers the people with the tools to transform their own environment. This is what architecture should be: architecture must become the craft of making our world where our knowledge and technology doesn't limit us but rather enables us to turn dreams of sustainable vertical urbanism into facts.

\section{Tall building typology and the city}

Historically in cities, the high-rise exists for totally commercial reasons. In such circumstance, the high rise is the result of high land prices. In order to compensate for the high cost of land, the cost needs to be apportioned to as much new built-up spaces as permitted until the potential income. What is a 'Tall Building'? The definition of tall building is best explained by the CTBUH, the central repository of ideas, technical and philosophical about tall buildings. For centuries, the 'average urban height' was established by the technology of the masonry terrace, of 5-7 storeys. Since the frame was developed, everything higher than the traditional urban average has a degree of tallness that is related to its technology and urban context. In the large cities, we think of anything 10-14 storeys and higher to be a tall building. (Habitat, 2015)
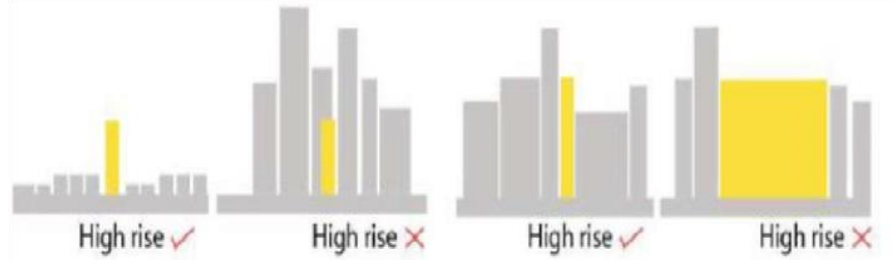

Figure 3 Height relative to context and proportion, Source CTBUH

The tall building acts as a possible solution to urban growth. Densification is likely to continue to be adopted in the world's major cities. If the size of recently urbanized population is any guide, then living in cities seems to have great 
appeal than residing in countryside. The size and the number of cities and the rate by which many of them are growing suggest that most people find them highly attractive and acceptable forms of settlement. (Yeang, 2006) Many people regard the expansion of their cities upward to optimize the city metropolitan land area as the most valuable economic and ecological option. Through Europe as London, Cologne, Stuttgart, Frankfurt, Istanbul, city centre planners are proposing increased densification of their central business districts and building over their cities, railway lines. Clearly this expansion must be well managed and relate to the projected built stock requirements of each individual city economic growth and built space rate. As we look more to the third dimension, vertically, this might be renamed as 'intensification' - not just increasing density, but increasing the range of functions. Urban transportation is a key to better density transport is more economic and effective if buildings are densely gathered around nodes, and dense buildings are more economic and effective if well served by mass transport. This energy justification applies not just to horizontal transportation systems, but also to vertical systems as well. Elevators now use a tiny proportion of tall building energy consumption compared to air conditioning or computer serves.
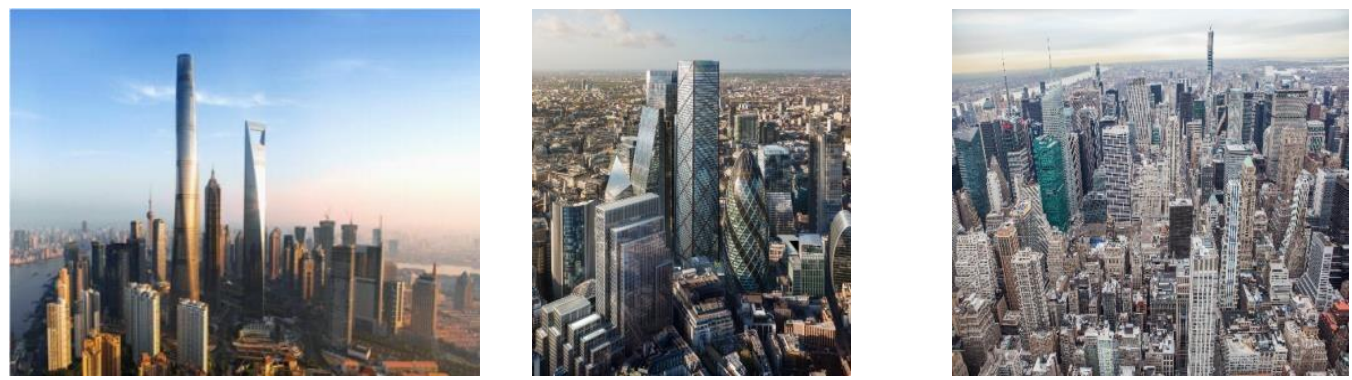

Figure 4. Poor Tall buildings typologies with the city infrastructure.

Cars and the concrete they must move on consumes land in highways and in parking areas. Private traffic also consumes and makes dangerous most of the streetscape that was formerly given to pedestrians and horse-drawn traffic. Future city centres must be planned for a much greater mix of uses than existed in the past with critical rethinking of its built configuration, its planning and its design in a way that better responds to its intensity and urbanistic needs of its inhabitants. (Yeang, 2006)

\section{Mixed use developments}

Human settlement has developed for centuries in mixed use patterns, which combines different functions as residential, commercial, cultural, educational and industrial zone. Mixed-use development is essential and important part of the regeneration and urban renewal process. (Howeler, 2003) The idea of mixed use tall buildings is not new through history, density, the value of land and the overlapping of functions have been inherently linked in Antiquity. The city states of warring periods developed borders, walls and moats in order to defend and define the distinction between the civilized and the wild. The main forms of movement and transportation at that time would have been by foot and horse. Consequently, programs such as work places, commerce and houses were located either in the same spaces or stacked atop of each other, and in many cases, there was no distinction between functions. Functions rather than being allocated in isolated part of the city, filled whatever space was available and through this, as the cities grew they formed a single hybrid entity. Mixed use development means building complex or neighbourhood that includes mixtures of land uses, where a diversity of activities and destinations are in walking distance to each other. This results in the same dynamic conditions that attract people to cities and neighbourhoods. Mostly the contemporary term of 'mixed use' applied to a single building complex is commonly used when residential uses are combined with offices, entertainment, shopping or other civic and public uses as libraries, school, parks and government service. (Ghel, 2010) The main concept of having vertical mixed use on one urban plot was originally created from the necessity of ever increasing urban densities in maturing cities around the world where, the land is limited and have a great value, and long transport between uses is time consuming. Vertical mixed use starts first in maturing Asian countries as Hong Kong, Singapore and China that. The unique benefits of having multiple building uses are that in the same area people can live, shop, work and recreate at the same complex. This vision has driven the success and the development of tall buildings worldwide. (Yager, 2015) Mixed use vertical development means the diversity of functions in tall buildings that uses vary from one floor to another creating more option activities for different users, design flexibility and city vitality than single use function building. (Qingdao, 2014) 


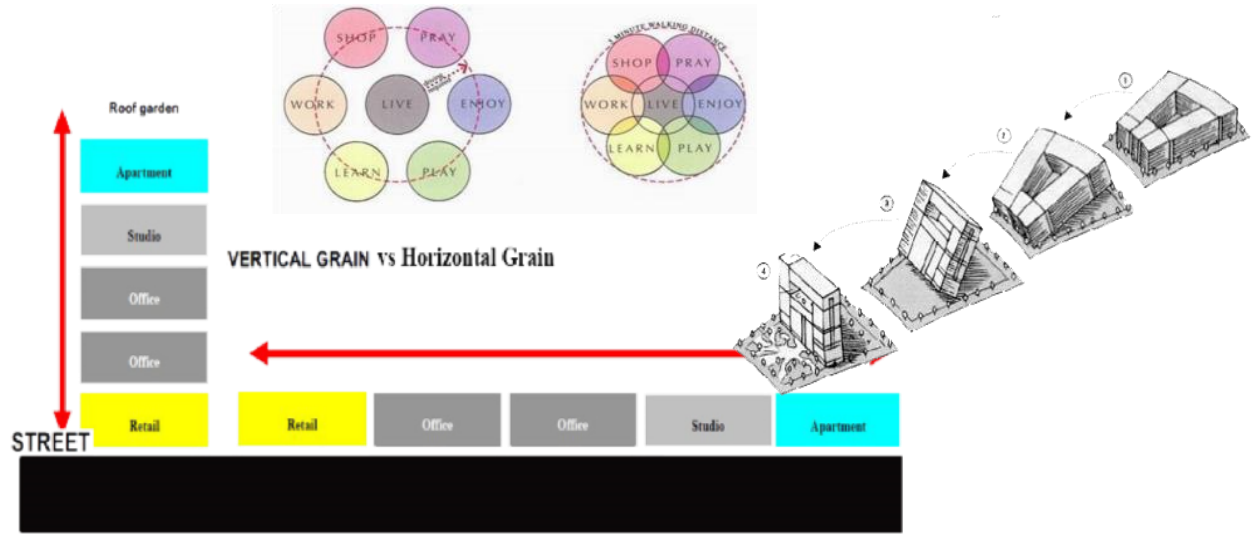

Figure 5- Vertical Grain VS Horizontal Grain, by: Author Above, Mirador, Madrid, MVRDV

\section{Potentials of having mixed use complex}

Mixed use complex is becoming a significant tool, for realizing the vertical urban development in the dense cities, Compared with single function buildings. Mixed use complexes provide synergetic effects that bring improved benefits for all functions, create higher spatial efficiency for the entirety of the building, and promote not only the surrounding communities but also the whole city by attracting more people to visit. Mixing the residential spaces with offices and commercial facilities creates more efficient use of the valuable land by mean of utilizing the building and space twentyfour hours with their different time occupancy use of the different functions. Potentially, this brings vitality to the city, adds life and safety to the street as people will be using the building within different time and activities during the day. Mixed use can make the building accessible by more residents, workers, visitors and students, increase the use of public transportation and reduce the reliance on car. Mixed use also provides short traveling distance between the residential and the work place for the people who live in the city, which results in reducing the excessive traffic load caused by owner driving commutes. Developers and investors view mixed use tall buildings to be less risky and more financially attract than single use high rise building due to its diversity of different functions that attract developers and enable financial survival through economic recessions. (Qingdao, 2014) Mixed use tall buildings promote convenient urban opportunities for residents to work, shop and interact within community and neighbourhood. The lifestyle of urban citizens at ground level takes advantage of public amenities such as parks, open spaces and public transit: with skill, something of this can be provided in the mixed use tall building. Good mixed-use design provides secure twenty-four hours' character in the city with more vital and vibrant urban environment that improves life in the city. Buildings and neighbourhoods with a mixture of uses and activities are more active and flexible to change as individual uses can be changed or replaced easily. We have to recognize that in a vertical structure this level of freedom is not available, except through periodic refurbishments or tenancy changes, such as offices becoming apartments, or apartments becoming small office-home office (SoHo) workspaces: the fundamental positions of skycourts and concourses remain fixed for life. (Groesbeck, 2012)

\section{Sustainability and quality of life in mixed use vertical complexes}

Sustainability literally means the ability to be sustained ...ie. To continue to have the same behaviour, quality of life, access to resources. The most definitive explanation of sustainability, which is based on the concept of sustainable development, first appeared in the Brundtland Report for the World Commission on Environment and Development (1987). The Report defined Sustainable development as:

"...Development that meets the needs of the present without compromising the ability of the future generations to meet their own needs."

Sustainability in vertical mixed-use development is a concept that involves taking a long-term view of environmental, economic and social issues. It should be recognized that the sustainability agenda varies across the world and that it continues to reflect political, economic and business priorities. (Yeang, 2006) (Holl, 2014) Sustainability is considered by the ability of achieving a mutually beneficial balance between environmental, economic and social issues which called "Triple bottom line" an example of this would be the reduction of waste through good management practices at site, such move has economic (less waste and less cost), social (social public spaces and vitality interaction inside the building) and Environmental (less material used, less energy consumed in transport). With regards to high density mixed use developments (Masanvi, 2000) defined four additional factors related to the quality of life: accessibility of urban spatial facilities, use of vehicles and technology, health and well-being, and social and cultural interaction. Masanvi also conducted a comparative study, of urban mixed and single use development. The study reported that urban high density mixed use developments can reduce vehicle use and can ensure dweller satisfaction in terms of health and social interaction. Mixing the work places, the living quarters, the daily needs and culture activities nearby can reduce the needs to travel by cars and also revitalize the urban environment. 

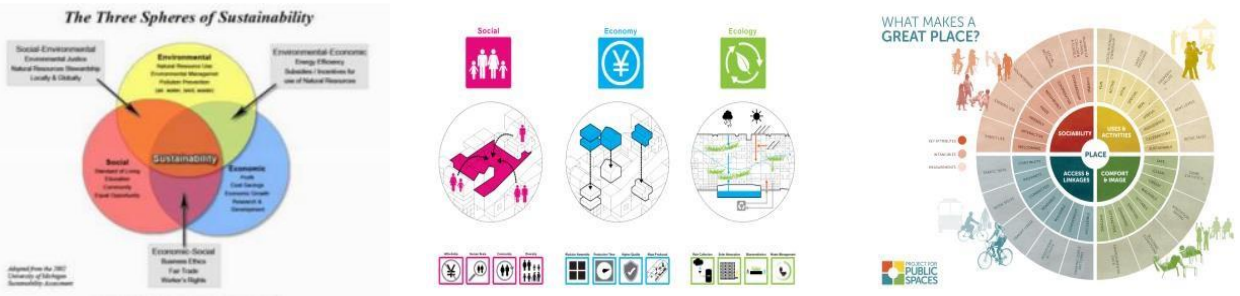

Figure 7- Vertical Grain VS Horizontal Grain, Done by: The Author

What makes a great vertical urbanism mixed use?

We all agree that 'community' is a good thing, but in a mixed-use building there are also the need for safety and security: the designer must devise way to keep shoppers out of office spaces, office workers out of primary school, children out of mechanical areas, and so on - a myriad of complex relationships or separations must be enabled, either through elevator zoning or electronic identification card and turnstiles. The sectional (or stacking) configuration of mixed use hybrid buildings take precedent over the planimetric. As an urbanist and architects, we must think first of building sectional configuration for the quality of sunlight, the dynamic of diagonal section movement, core circulation and the synergy between different functions. The old condition of linear perspective (from planimetric projections) disappears behind us as modern urban life presents multiple horizons and multiple vanishing points. The further affirmation of the diagonal and the vertical in new three-dimensional experience is the challenge of the 21st century. (Holl, 2014) Freedom of invention is a particular potential of vertical mixed-use hybrid buildings: unprecedented ideas may drive the design of new building types. In certain way, these new buildings might illuminate the unique character of the site and city they arise in.
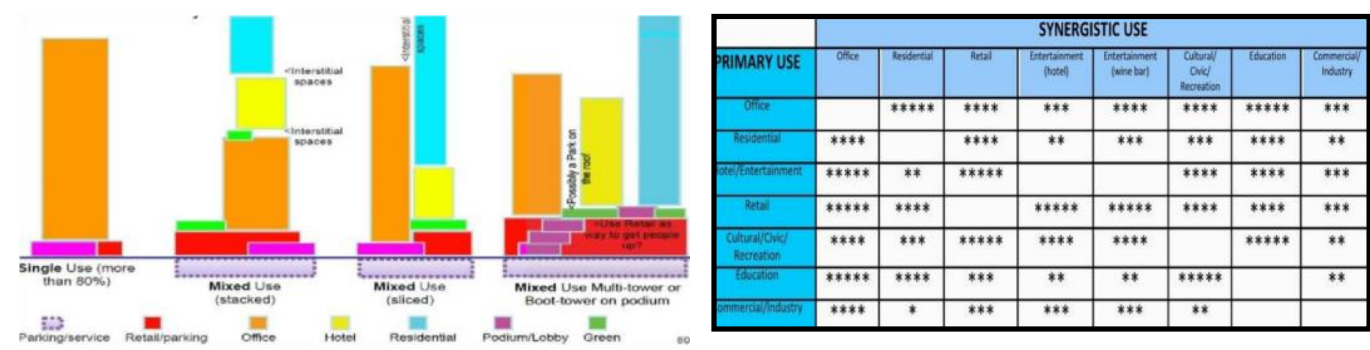

Figure 6- Vertical Grain VS Horizontal Grain, Done by: The Author

There are several aspects that characterize the positive path of sustainable vertical mixed-use hybrid building in the creation of inspiring and active new urban spaces which are synergy between building functions, public spaces formation, freedom of new concepts, dynamic of section, $21^{\text {st }}$ century cities as incubators, living/working/recreating and cultural social condensers and super green architecture. (Holl, 2014) 'Hybrid buildings' had not yet been classified as a unique building type, usually grouped under 'mixed-use' till 1985. Fentono argued that there was a distinct different between hybrid buildings and mixed-use, in that the individual programs relate to one another with appropriate accessibility and positioning give an opportunity for synergy - with density, $2+2$ equal 4 , but with intensity, $2+2$ can equal 5. The distinction of a hybrid from other mixed-use mega structures are defined by these buildings which retain the underlying city grid and are contained within single form of a building. A mixed use building stacked vertically can integrate different programs within a single structure building, like the Hancock Center, Chicago (1969) or Hysan Place, Hong Kong (2012). Functions can be separated and work well individually according to position in the stack. The building's physical appearance may image as a single whole building. Each interior may have its own spatial character, but most of the circulation is enabled by zoned local and shuttle elevators, with card-controlled access rights.
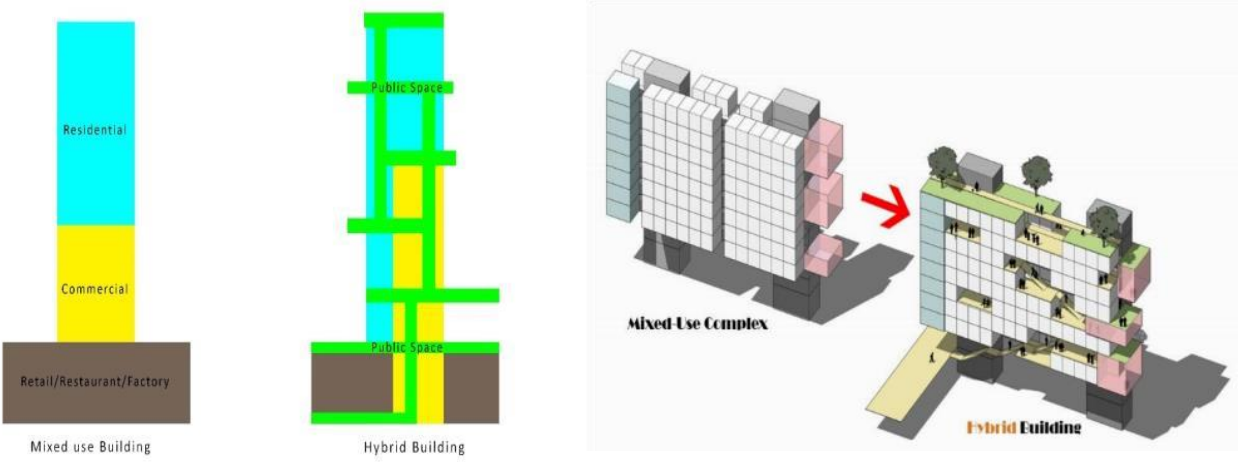

Figure 6- Vertical Grain VS Horizontal Grain, Done by: The Author 
The hybrid vertical building includes both the city context and the architecture itself, which is characterized by a high programmatic complexity. It seems like an improved version of the mixed use cluster of buildings, able to solve the problems related to horizontal mixed use such as land scarcity, over-extended infrastructure of roads and flyovers. Although the main idea of hybrid mixed use building is to mix various programs within a single building, the main difference between that and a cluster is the ideal arrangement of internal space and users' interaction.
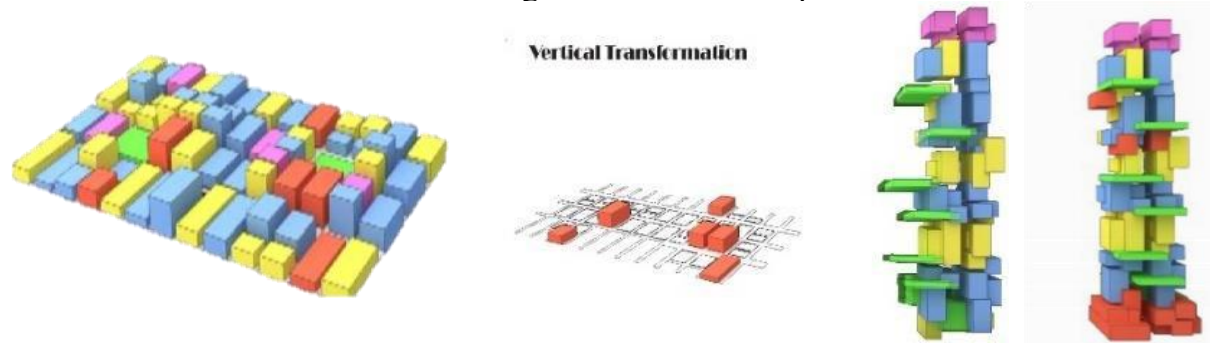

Figure 6- Vertical urbanism diagram, MVRDV, edited by the Author.

The hybrid building is not designed to just meet the basic demand, working and living convenience for the individuals; it is to be designed to include memorable and interesting interior spaces, engaged in their context, and resembling a community. Stephen Holl said "hybrids are incomplete and necessarily rely on the organization of the whole in a way that reorganizes the social dimension of the building." (Holl, 2014) Hybrid building is a well planned and configured product, sharing common areas or other high altitude linking spaces, which makes the hybrid as a whole building. Each part complements or relies on each part. The first four generations of tall buildings hide functions behind a single façade. That was the 'Conventional Wisdom' evolving from stone-faced frame structures in the early $20^{\text {th }}$ century to excessive dependence on glass since 1950. We need a paradigm change. Buildings should be allowed to be 'heterogenous' and more honest in showing functions. Facades can reflect the function contained: balconies with operable windows for residential, efficient high performance facades with solar shading and energy generation for offices. Hybrid buildings act as 'cities in the sky', mixing the programmed functions of an town or city. Led by new constructions in Asia and the middle east, large buildings can include a wide range of functions to allow certain degrees of urban completeness. The ability to provide the level of diversity available in urban zones make these buildings into microcosms of the city. Also when there are isolated or harsh surroundings, like a desert for instance, these buildings create a defensive or protective space for inhabitants much like walled cities of antiquity. There are many theoretical examples such as the 'hyper building' by OMA and theoretical utopias like 'sky city' by the Takenaka corporation a kilometer-high structure housing 13,500 people. More recent example includes project by Steven Holl in Shenzhen and Beijing. (Holl, 2014)

The examples illustrated in Figures 7 and 8 are by Chinese masters students at the University of Nottingham Tall Building Studio. These projects for the city of Jakarta demonstrate a number of buildable visions of mixed use buildings, which by virtue of the synergetic combination of functions and horizontal connectivity, move the whole discussion on from 'mixed use' to 'hybrid' containers for sustainable vertical urbanism. They address the peculiarly Indonesian conditions of culture, context and climate, instead of imposing a standard glass tower, like a prototype from Chicago, onto an equatorial city. There are already too many of these glassy International-style 'mistakes' in Middle Eastern and tropical cities.

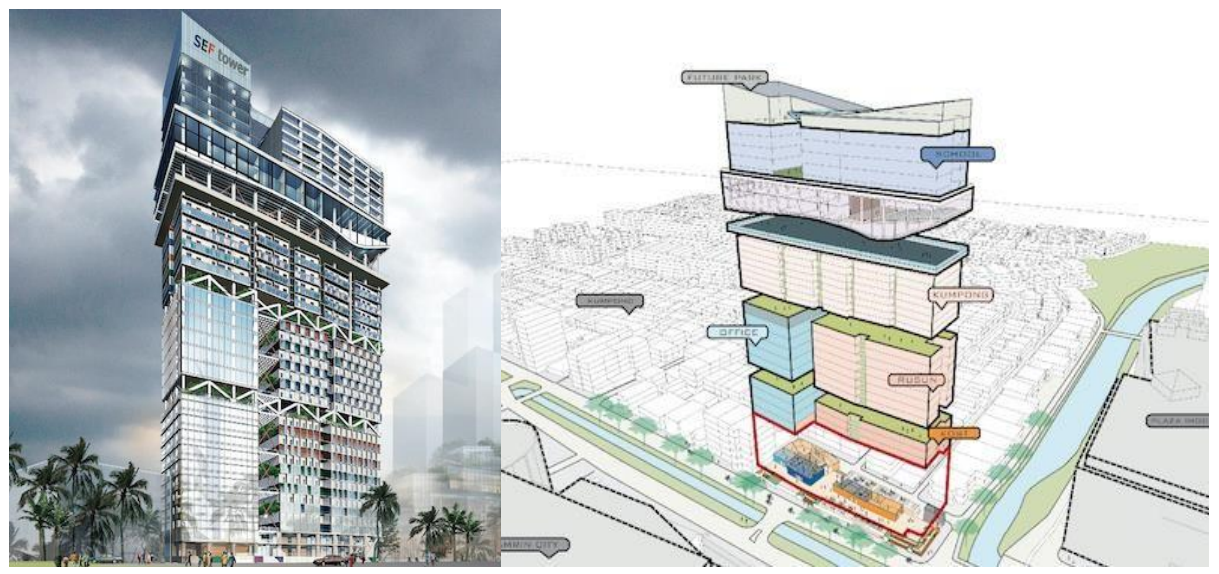

Figure 7: Theoretical hybrid building for Jakarta, incorporating motorcycle parking, retail, markets, mosque, wedding chapel, skypark, community spaces, school, energy-education park, low income housing medium income housing, offices: Zhenyu Li, University of Nottingham Tall Building Studio 2017 

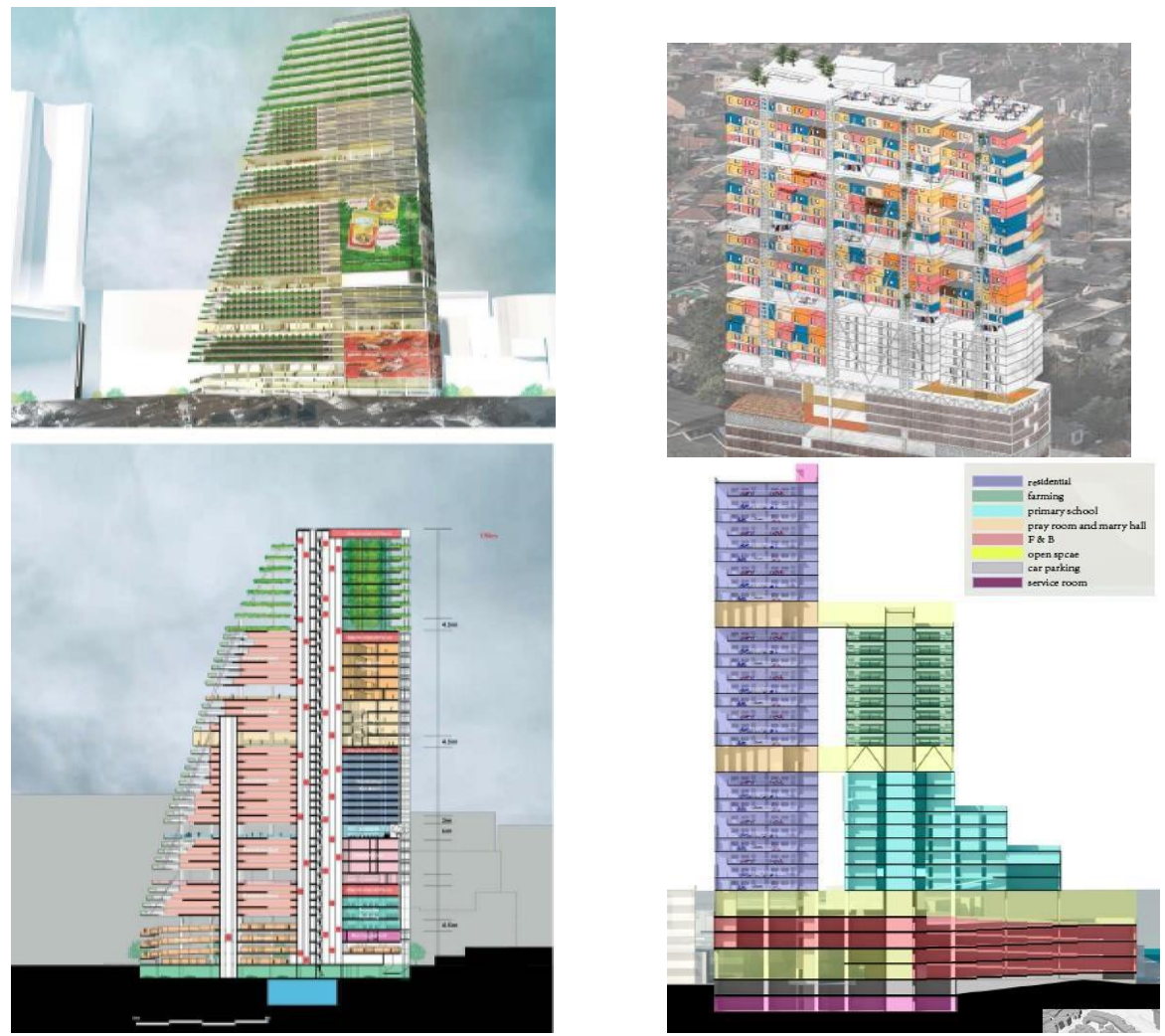

Figure 8: Theoretical hybrid buildings for Jakarta, incorporating motorcycle parking, retail, markets, mosque, wedding chapel, skypark, community spaces, school, vertical farming, manufacturing, low income housing medium income housing, offices. Top right, 'Always Building' megastructure with self-build housing. by: Bin Ye, Chenwei Zhang, Weijia Yang, Wenyuan Zhang: University of Nottingham Tall Building Studio 2017

Discussion and Future possibilities (thinking about designing cities in different way) China is urbanizing rapidly. From 2002 more than 250 million people moved from farm areas to China. In China, today there are 700 million Chinese citizens living in urban area. Thinking about this population in the next two decades, another 300 million people will move into urban areas in China; that's equivalent to the entire population of the United States. China, by 2025, will build enough skyscrapers to fill ten New York sized cities every single year. (Winey, 2012) Analyzing two examples: the first one is Houston, which is low rise low density city (with a high-rise CBD), that has an average population density 3,500 per square mile. Hong Kong and its 'New Territories'on the other hand has a population density of almost 93000 people per square mile. Houston uses 34 times amount of land area and natural resources than Hong Kong does. Hong Kong is 27 times denser than Houston and contains a huge proportion of forested country parks within its boundary. The reliance on cars in Houston, $\mathrm{CO}_{2}$ emission and the levels of pollution is very different. In Hong Kong, mass transport, walking and taxis is mainly the way that people go around. These statistics do not necessarily mean that all cities should become denser and go higher. It just indicates circumstantially that density is a more sustainable model for building a great city. (Winey, 2012) Looking to other examples are Beijing and Guangzhou: these were historically low-rise cities, and morphed into cities of high rise monocultural buildings, with poor planning, which included wiping out traditional lowrise high-density neighbourhoods, driving through expressways, and parcelling land into grid plots for high rise. For the citizen, this lost the city's identity and vitality. In the past, Beijing was a city where people can work, play and navigate the city by bike or walking. Now, people cannot get around Beijing without getting in a taxi or car. The typical ring road in Beijing is an 18-lane highway, which is impossible for any person to try to cross it. Jakarta, the world's second largest city, is bipolar, with vast low-rise high-density 'kampung' areas, gleaming glass towers, gigantic block-like shopping complexes, no metro system, and reliance on 27 million motorcycles to enable the city to function. The theoretical hybrid towers illustrated above (Figs $7 \& 8$ ) are a new paradigm for urban design, addressing the needs of the masses, not the elite. Special elevators bring motorcycles up to the apartment levels. Retail supports street food, fresh food markets and workshops. Vertical urbanism is about looking to the cities with a new paradigm - imagining the possibilities of breaking the boundaries between buildings and cities. Start thinking and have a wide look on what makes a great city - they can be great places to live, great places to shop and eat, viable business preferably close to where you live, culture and entertainment, parks and open spaces and well connected public transit. Looking to that prototype of horizontal city planning, we can think in completely different ways, those of 3D dimensions, adapting as human development progresses along the $4^{\text {th }}$ dimension, that of time. All the great elements of the city texture and fabric could be organized with a greater degree of vertical master planning, with horizontal connectivity. We should not be designating a district for high-rise building, as it is not about height and being tall. Vertical Hybrids are more about urban structures, that combine city life and vitality, that can have housing, hotels, offices, cultural venues, vertical farming, retail, entertainment venues, parks, open spaces and well connected to public transport, linked to the major subways and the major bus routes, which allow people to come from all parts of the city. 


\section{References}

[1].Ghel, J., 2010. Cities for People. 1 ed. Washington: sland Press.

[2].Groesbeck, C., 2012. Tall buildings in future development of Metropolition university

[3].(CTBUH research paper). [Online]

[4].Available at: http://global.ctbuh.org/resources/papers/download/989-tall-buildings-infuture-development-ofmetropolitan-universities.pdf [Accessed 4 January 2017].

[5].Habitat, T. C. o. T. b. a. U., 2015. CTBUH Height Criteria for measuring and defining Tall buildings. [Online]

[6].Available at: http://www.ctbuh.org/LinkClick.aspx?fileticket=zvoB1S4nMug = [Accessed 17 July 2017].

[7].Holl, S., 2014. THIS IS HYBRID. London: a+t research group.

[8].Howeler, E., 2003. Skyscraper design of the recent past and for the near future.

[9].London - United Kingdom : Thames and Hudson.

[10]. Qingdao, G., 2014. VERTICAL TRANSPORATION \& LOGISTICS IN MIXED-USE (CTBUH 2014 SHANGHAI CONFERENCE). [Online]

[11]. Available at: http://lerchbates.com/assets/images/CorpColl/_LB524R_072215_Brochure.pdf [Accessed 2 January 2017].

[12]. Spaces, P. o. p., 2009. What Makes a Successful Place?. [Online] Available at: http://www.pps.org/reference/grplacefeat/ [Accessed 24 December 2016].

[13]. Winey, D., 2012. Building Vertical Cities: Daniel Winey at TEDxConnecticutCollege.

[14]. [Online]

[15]. Available at: https://www.youtube.com/watch?v=Agei8pMxi9g [Accessed 28 July 2017].

[16]. Yager, G., 2015. High Density mixed use development and the Guiyang riverside theatre project (CTBUH research paper). [Online]

[17]. Available at: http://global.ctbuh.org/resources/papers/download/2418-high-density-mixeduse-developments-andthe-guiyang-riverside-theatre-project.pdf [Accessed 28 December 2016].

[18]. Yeang, K., 2006. Reinventing The skyscrapers. Chicago: WIELY Academy . 